\title{
National Epidemiological Case-Control Study of Pharmacological Smoking Cessation Treatment in Danish Patients with Chronic Obstructive Pulmonary Disease
}

\author{
Dea Kejlberg Andelius' \\ Ole Hilberg ${ }^{2,3}$ \\ Rikke Ibsen ${ }^{4}$ \\ Anders Løkke iD ${ }^{2,3}$ \\ 'Department of Pediatrics and \\ Adolescent Medicine, Aarhus University \\ Hospital, Aarhus, Denmark; ${ }^{2}$ Department \\ of Medicine, Vejle, Little Belt Hospital, \\ Vejle, Denmark; ${ }^{3}$ Department of Regional \\ Health Research, University of Southern \\ Denmark, Odense, Denmark; ${ }^{4} \mathrm{i} 2 \mathrm{minds}$, \\ Aarhus, 8000, Denmark
}

\begin{abstract}
Background: Chronic obstructive pulmonary disease (COPD) is a progressive lung disease that is mainly caused by smoking, and most patients with COPD are either former or current smokers. The optimal way to slow down disease progression and reduce overall mortality is for patients to stop smoking. Patients with COPD are known to have lower socio-economic status and to be more nicotine-dependent than most other smokers and therefore face difficulties when attempting to quit smoking. Pharmacological smoking cessation treatment is known to be the most effective. However, the extent to which this treatment is actually offered to Danish smokers with COPD is unknown.
\end{abstract}

Aim: The aim of this study was to investigate if patients with COPD were more likely to redeem a prescription for smoking cessation medication compared with matched controls.

Materials and Methods: The study was designed as a registry-based, non-interventional case-control study. All Danish patients with COPD (ICD-10-code J 44 chronic obstructive pulmonary disease) diagnosed between 2009 and 2015 were included (130,797 cases). Controls $(252,216)$ were matched on age, gender and geography. Primary outcome was the number of redeemed prescriptions for smoking cessation medication.

Results: We found that $12 \%$ of patients with COPD redeemed a prescription for smoking cessation medication during the eight-year study period. The odds ratio (OR) for redeeming a prescription on smoking cessation medicine was OR 6.22 for patients with COPD compared with their matched controls. We also found that patients with COPD were more likely to redeem smoking cessation medication if they were younger, female or single.

Conclusion: There is substantial room for improvement with respect to pharmacological smoking cessation treatment in Danish patients with COPD. In-depth knowledge of factors contributing to the patients choice of smoking cessation treatment might allow for more personalized guidance of patients with COPD.

Keywords: nicotine, bupropion, varenicline, smoking cessation, COPD

\section{Introduction}

Chronic obstructive pulmonary disease (COPD) is a global disease characterized by chronic bronchitis, emphysema and an irreversible loss of lung function. ${ }^{1}$ The diagnostic criteria of COPD are a post-bronchodilator lung function with FEV1 (forced expiratory volume in 1 second)/FVC (forced vital capacity) $<0.70 .^{2}$ The most common cause of COPD is smoking, but air pollution and occupational exposure are other important causes. ${ }^{3}$ Despite various etiologies, $97 \%$ of Danish
Correspondence: Dea Kejlberg Andelius Email dea-jensen@hotmail.com 
patients with COPD have a history of smoking. ${ }^{4}$ The worldwide prevalence of COPD in people over 30 years of age is estimated to be approximately $10 \%$, and the number is rising. ${ }^{5,6}$ Denmark has a similar or even higher prevalence. ${ }^{7,8}$ Despite public campaigns, increasing cigarette prices, and public bans on smoking in certain areas, such as hospitals, train stations, and bars, $23 \%$ of the adult Danish population are currently smokers. ${ }^{9}$ The prevalence of smoking has been steady for some years (15-29 years of age: $29 \%, 30-59$ years of age: $25 \%, 60+$ years of age: $16 \%){ }^{9}$ Unfortunately, there has been a slight increase from 2018 in number of smokers, especially among young adults. ${ }^{9}$

The societal costs of COPD are considerable. ${ }^{10,11}$ The estimated annual costs per person for COPD-related health care contacts in Denmark is 8572 EUR. ${ }^{12}$ The majority of costs relate to primary care and in-hospital care during exacerbations. It is therefore essential to slow down disease progression, to ensure patients' quality of life and limit socio-economic costs.

Smoking plays a major role not only in COPD but also in other diseases, eg lung cancer and cardiovascular disease, leading to a more rapid disease progression and higher mortality. ${ }^{13}$ Smoking cessation is therefore essential in the treatment of patients with COPD; ${ }^{14,15}$ not only because smoking cessation delays disease progression but also because it reduces respiratory symptoms and increases survival. ${ }^{16-23}$ Previous studies have shown that smokers with COPD are more nicotine dependent than lung healthy smokers and find it more difficult to quit smoking. ${ }^{13,24}$

Despite the fact that smoking cessation is the best treatment for COPD, approximately $33 \%$ of patients with moderate or severe COPD are current smokers. ${ }^{4,25}$ It has been estimated that $62 \%$ of Danish smokers have a desire to quit smoking. ${ }^{9}$ There are various smoking cessation strategies. Although non-pharmacological treatments, such as motivational therapy, have been shown to be effective, ${ }^{26}$ it is inferior to pharmacological treatments such as nicotine replacement therapy (NRT), bupropion and varenicline. A combination of motivational therapy and pharmacological treatment seems to be the most effective. $^{27}$ The one-year quit rate differs considerably between studies. The reported quit rates are approximately $10 \%$ for bupropion, $15 \%$ for NRT, $20 \%$ for varenicline and $8 \%$ for placebo. ${ }^{15,28-30}$ Combined with motivational therapy, the quit rates are higher: approximately $25 \%$ for bupropion and NRT, and $33 \%$ for varenicline. ${ }^{15}$
Bupropion and varenicline are both taken for about three months, whereas NRT is often used for a longer period of time. $^{15,31}$

Smoking cessation medication is not part of the Danish national reimbursement system. This is in line with other countries in northern Europe and many other countries worldwide. $^{32}$ The price for the recommended 12-week treatment is 120 EUR for bupropion $\left(\mathrm{Zyban}^{\mathbb{R}}\right.$, GlaxoSmithKline Pharma) and 360 EUR for varenicline (Champix ${ }^{\circledR}$, Pfizer). The price of NRT varies and it is an over-the-counter drug; the recommended duration of treatment differs.

Patients and society spend a considerable amount of money on expensive inhaled medication; ${ }^{33}$ money that would be better spent supporting the use of smoking cessation medication (eg, by lowering the patient's share of the cost) and on counselling. ${ }^{34}$

The aim of this study was to describe the extent to which patients with COPD purchased pharmacological smoking cessation treatment, to identify individual-level factors affecting choice of smoking cessation treatment, and to use this knowledge to optimize future smoking cessation counseling for smokers with COPD.

Since patients with COPD typically smoke more than the background population, we hypothesized that patients with COPD collect more smoking cessation medication than matched controls. ${ }^{4,35}$

\section{Methods and Materials Study Design}

The study was a retrospective non-interventional registry study.

\section{Data Collection}

In Denmark, all Danish citizens have a unique Civil Registration System (CPR) number that enables us to link individual data from different registries. ${ }^{36} \mathrm{We}$ included all Danish patients with a diagnosis of COPD treated in Danish hospitals between 2009 and 2015. Data were collected from the Danish National Patient Registry, a complete nationwide registry, covering all nonpsychiatric contacts to the secondary health sector in Denmark. $^{36}$ The ICD-10 code used to identify patients with COPD was J44.x (chronic obstructive pulmonary disease). We excluded patients under the age of 30 and patients who died in 2009. 
Each patient was matched with two controls without a COPD diagnosis in the period 1998 to 2015 . We matched patients and controls on age, gender and geography. Descriptive statistics are from the index year.

Data on age, gender and geography were extracted from the Danish Civil Registration System. ${ }^{37}$ Information about socioeconomic status, educational level, and marital status came from Statistics Denmark.

When a patient redeems a prescription in a Danish pharmacy it is registered in the Danish National Prescription Registry, and linked to the patients CPR-

\section{Inclusion}

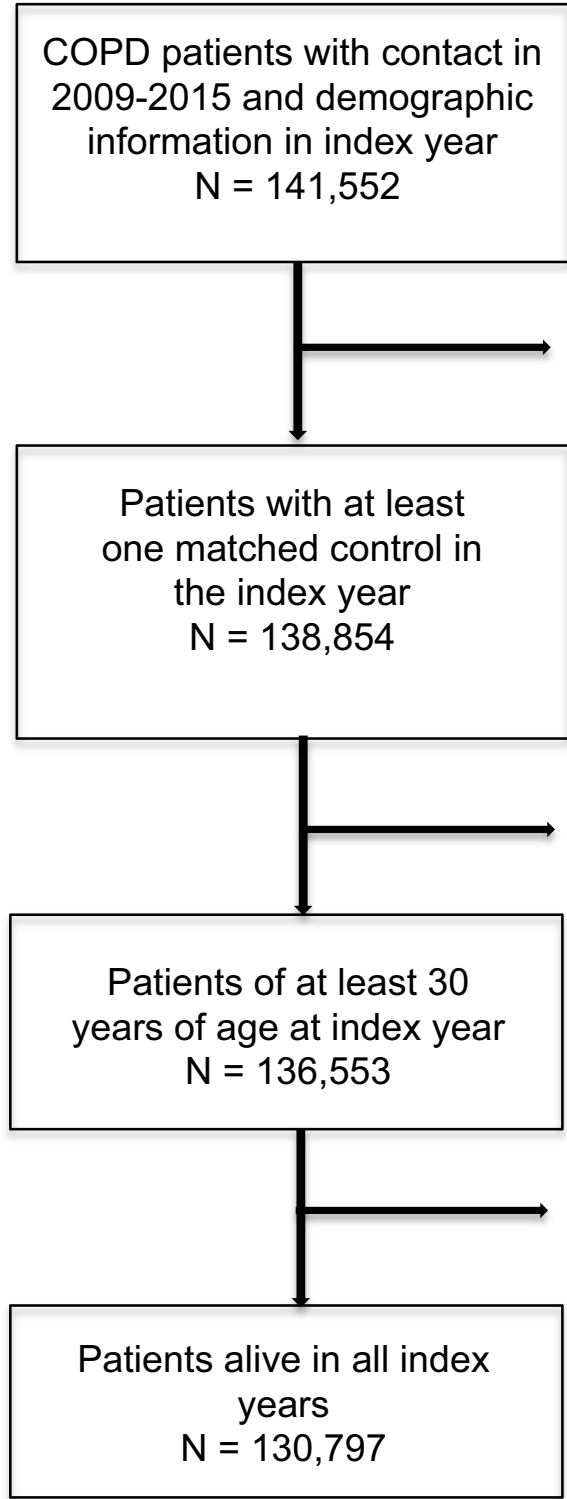

number. ${ }^{38}$ Only the prescriptions that are also redeemed are registered. All redeemed prescriptions with the Anatomical Therapeutic Chemical (ATC) Classification codes N07BA01 (nicotine replacement therapy (NRT)), N06AX12 (bupropion), or N07BA03 (varenicline) were included.

Figure 1 shows the inclusion process. We identified 142,273 people with a primary or secondary COPD diagnosis between 2009 and 2015. 141,552 patients with demographic information were included, and 2698 patients were excluded because there were no matched controls in

\section{Exclusion}

\section{Patients with no matched control} in the index year

$$
\mathrm{N}=2,698
$$

\section{Patients $<30$ years of age at index year $\mathrm{N}=2,301$}

Died in 2009

$\mathrm{N}=5,756$

Figure I Flow diagram for patient inclusion. 
the index year. A total of 2301 patients under 30 years of age were excluded and 5756 patients were excluded because they died in 2009. Each case was matched with two controls. Due to the narrow matching criteria, we did not succeed in identifying 9378 controls (approx. 4\%), but all included cases were matched with at least one control.

\section{Outcome}

The primary outcome was a number of redeemed prescriptions for smoking cessation medication with one of the following ATC-codes: N07BA01, N07BA03, or N06AX12.

\section{Statistics}

To compare socioeconomic factors for cases and controls on the redemption of prescriptions, we used a conditional logistic regression model with case $=1$, control $=0$. We corrected for socioeconomic factors using Statistics Denmark model Socio13. ${ }^{39}$ Statistical analysis was performed using SAS 9.4 TS Level 1M5 (SAS, Inc., Cary, NC, USA).

An attempt to quit smoking was defined as the redemption of a prescription for smoking cessation medication in the period between 2009 and 2015. Subsequent attempts were defined as redemption of a prescription for smoking cessation medication more than six months after redeeming the previous prescription, plus the defined daily dosage (DDD) of the previously redeemed prescriptions.

\section{Ethics}

The study was approved by the Danish Data Protection Agency. In accordance with Danish law, patient consent and ethics committee approval were not required, as the design was a register-based study that did not contain any traceable patient data. Guidelines outlined in the World Medical Association Helsinki Declaration were followed.

\section{Results}

Table 1 displays cohort demographics. Mean age for cases was 69.4 years and for controls 69.2 years; $47 \%$ were women in both groups. The two groups were significantly different in terms of marital status, socio-economic factors and educational level. $61 \%$ of controls were married compared with only $49 \%$ of the cases. $24 \%$ of controls were still active in the labor market, whereas this was only the case for $12 \%$ of the cases.

Table 2 shows the number of cases and controls who redeemed a prescription for smoking cessation medication
Table I Basic Characteristics

\begin{tabular}{|l|c|c|c|c|}
\hline \multirow{2}{*}{ Number of People } & \multicolumn{2}{|c|}{ Case } & \multicolumn{2}{c|}{ Control } \\
\cline { 2 - 5 } & \multicolumn{2}{|c|}{130,797} & \multicolumn{2}{c|}{252,216} \\
\cline { 2 - 5 } & Mean & Std. & Mean & Std. \\
\hline \multirow{2}{*}{ Age } & 69.4 & 11.7 & 69.2 & 11.7 \\
\cline { 2 - 5 } & $\mathrm{N}$ & $\%$-share & $\mathrm{N}$ & $\%$-share \\
\hline Gender & & & & \\
Male & 61,605 & 47.1 & 118,500 & 47 \\
Female & 69,192 & 52.9 & 133,716 & 53 \\
\hline Marital status & & & & \\
Married/co-habiting & 63,537 & 48.6 & 153,007 & 60.7 \\
Single & 67,260 & 51.4 & 99,209 & 39.3 \\
\hline Socioeconomics & & & & \\
Old age pension & 89,001 & 68 & 164,419 & 65.2 \\
Disibility pension & 16,349 & 12.5 & 9674 & 3.8 \\
Early retirement & 4212 & 3.2 & 10,027 & 4 \\
In education & 906 & 0.7 & 2411 & 1,0 \\
Employed & 15,111 & 11.6 & 61,010 & 24.2 \\
Sickpay/leave & 1187 & 0.9 & 830 & 0.3 \\
Social security & 3429 & 2.6 & 2422 & 1,0 \\
Unemployment benefit & 602 & 0.5 & 1423 & 0.6 \\
\hline
\end{tabular}

between 2009 and 2015. A total of $12.1 \%$ of the cases redeemed a prescription for smoking cessation medication; $5.3 \%$ redeemed a prescription for NRT, $6.4 \%$ for varenicline and $1.7 \%$ for bupropion. Of the controls, $2.1 \%$ redeemed a prescription. A total of $0.6 \%$ redeemed a prescription for NRT, $1.3 \%$ for varenicline and $0.3 \%$ for bupropion.

Among both cases and controls, people aged between 40 and 64 redeemed the majority of prescriptions.

A total of $13.4 \%$ of female cases redeemed any kind of smoking cessation medication, whereas this only applied to $10.7 \%$ of the men. The same pattern was seen for all the subtypes of smoking cessation medication. In the control group, there was no difference between genders.

In both groups, singles collected more NRT than cohabiting participants.

Concerning socioeconomic factors, we found that people receiving a disability pension had the highest proportion of redeemed prescriptions for smoking cessation medication among both cases and controls $(21.8 \%$ of cases, $5.6 \%$ of controls).

Figure $2 \mathrm{~A}$ and $\mathrm{B}$ shows the distribution of the three types of redeemed smoking cessation medication. Overall, 


\begin{tabular}{|c|c|c|c|c|c|c|c|}
\hline \multirow{3}{*}{ 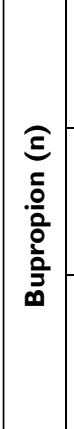 } & \multicolumn{2}{|r|}{ 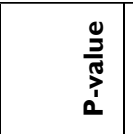 } & \multirow[b]{2}{*}{$\frac{\widehat{m}}{\stackrel{\varrho}{\varrho}}$} & \multirow{2}{*}{ 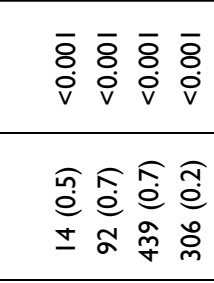 } & \multirow{2}{*}{ 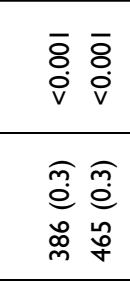 } & \multirow{2}{*}{ 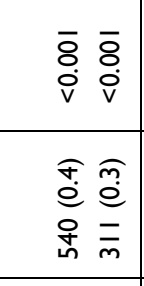 } & \multirow{2}{*}{ 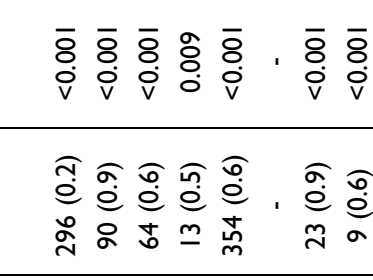 } \\
\hline & 家 & $\stackrel{\bigodot}{=}$ & & & & & \\
\hline & נ̋ & 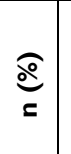 & 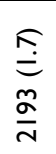 & 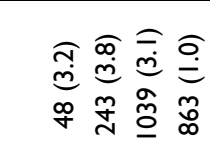 & 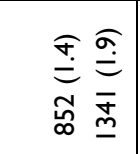 & 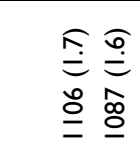 & 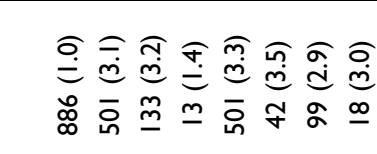 \\
\hline & & 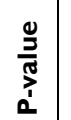 & & 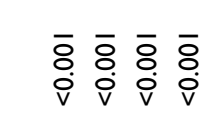 & $\begin{array}{l}\bar{o} \\
\overline{0} \\
\dot{0} \\
\dot{v} \\
v\end{array}$ & $\begin{array}{l}\overline{0} \\
\bar{i} \\
\dot{0} \\
\dot{0}\end{array}$ & 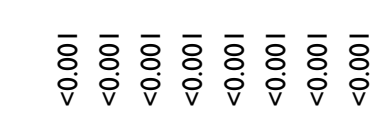 \\
\hline 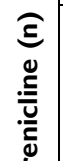 & 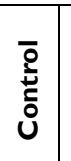 & $\stackrel{\overbrace{}}{=}$ & 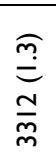 & 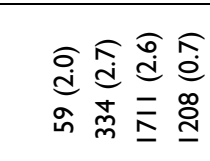 & 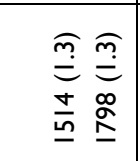 & 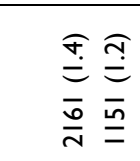 & 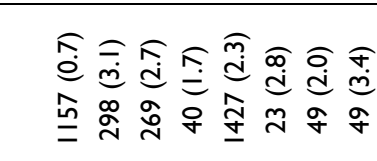 \\
\hline$>$ & נ̃ & $\stackrel{\overbrace{}}{\varrho}$ & \begin{tabular}{l}
\multirow{f}{*}{} \\
$\stackrel{0}{0}$ \\
$\hat{f}$ \\
$\infty$
\end{tabular} & 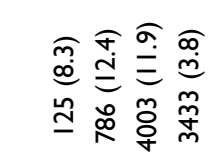 & 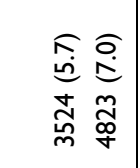 & 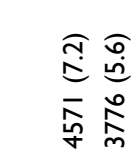 & 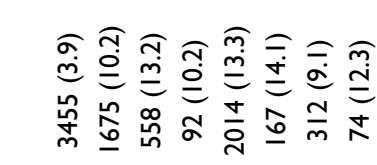 \\
\hline 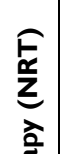 & & 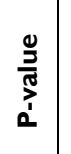 & & 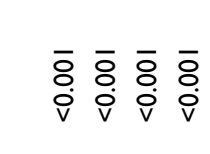 & $\begin{array}{l}\bar{\delta} \\
\bar{o} \\
\dot{0} \\
\dot{v} \\
\mathrm{v}\end{array}$ & $\begin{array}{l}\bar{o} \\
\overline{0} \\
\dot{0} \\
\dot{0}\end{array}$ & 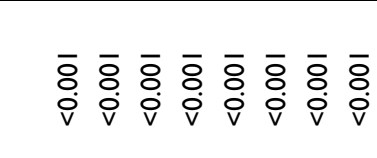 \\
\hline 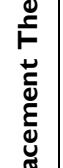 & 苞 & $\stackrel{\overbrace{}}{\simeq}$ & 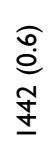 & 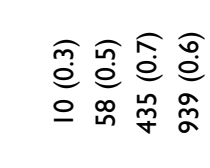 & 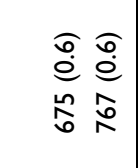 & 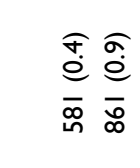 & 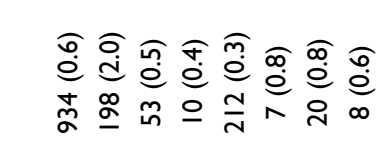 \\
\hline 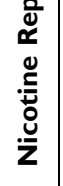 & נ̋ & $\stackrel{\overbrace{}}{=}$ & 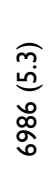 & 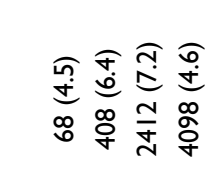 & 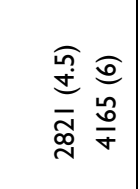 & 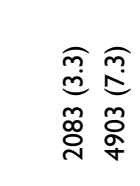 & 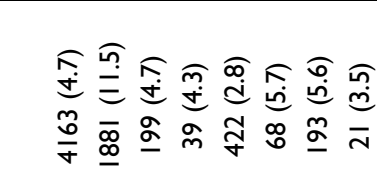 \\
\hline & & 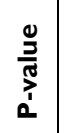 & & 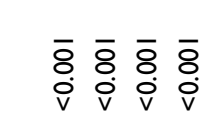 & $\begin{array}{l}\bar{\delta} \\
\bar{o} \\
\dot{0} \\
\dot{v} \\
v\end{array}$ & के & 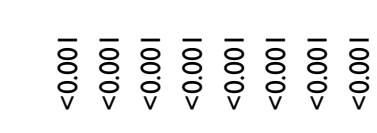 \\
\hline 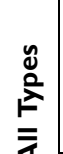 & 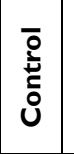 & 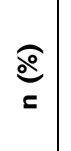 & $\begin{array}{l}\widehat{\bar{i}} \\
\overline{\bar{M}}\end{array}$ & 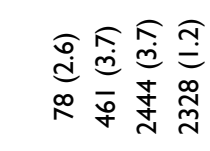 & 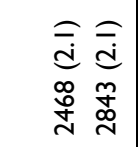 & 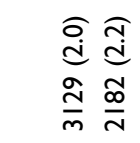 & 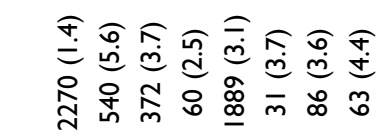 \\
\hline & ֻू & $\underset{=}{\stackrel{\varrho}{巳}}$ & 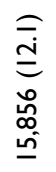 & 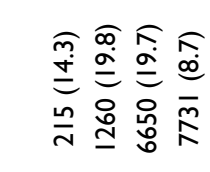 & 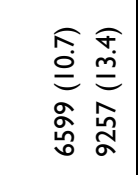 & 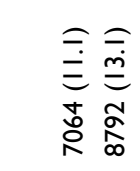 & 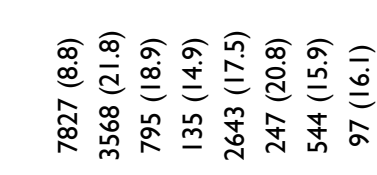 \\
\hline & & & 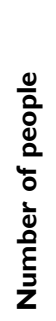 & 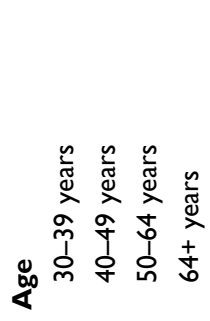 & 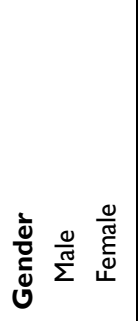 & 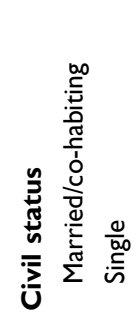 & 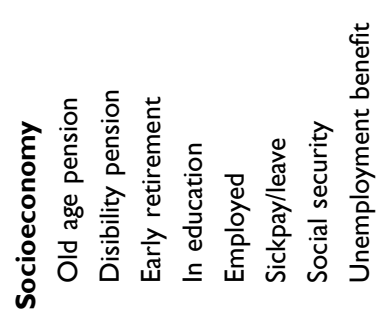 \\
\hline
\end{tabular}




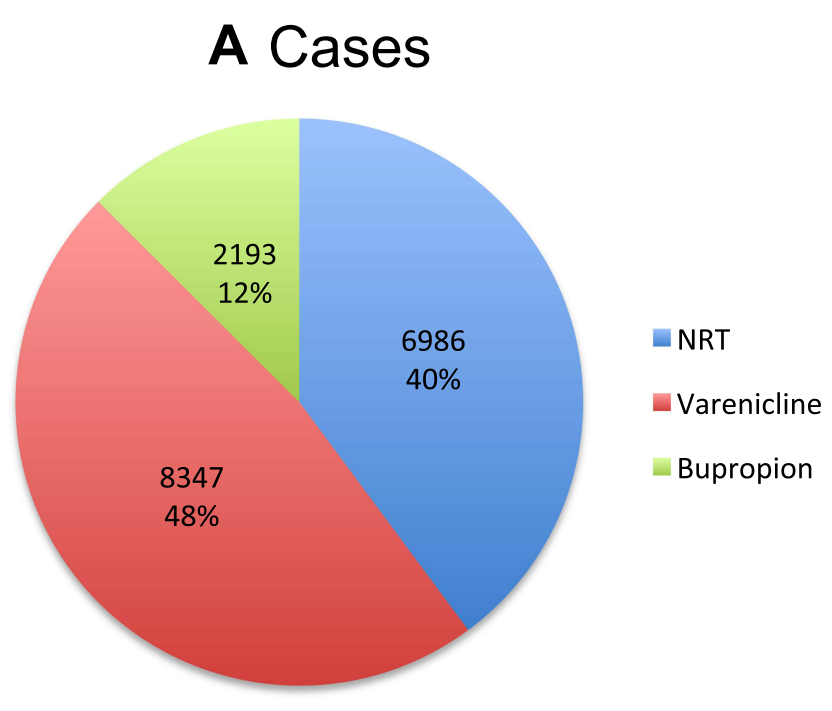

B Controls

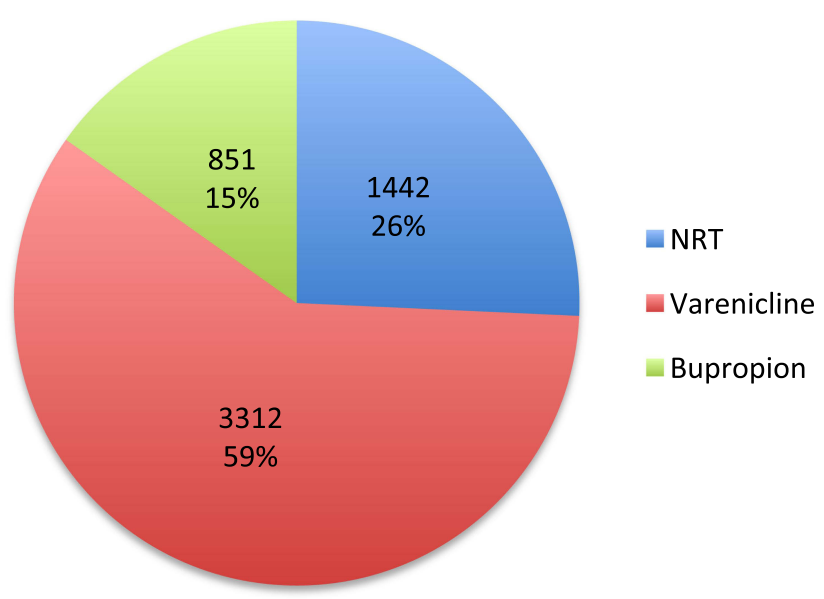

Figure 2 Distribution of the different kind of smoking cessation medication among cases (A) and controls (B).

bupropion was the least redeemed in both groups, whereas varenicline was the most frequently redeemed. Cases redeemed more NRT medication than controls.

Table 3 describes cases only. Among patients with COPD, the probability of redeeming smoking cessation medication diminished with age. The probability decreased by $3 \%$ (odds ratio (OR) 0.96 ) with every year a patient got older. The probability of redeeming smoking cessation medication was lower among men (OR 0.77) compared to women, and among married/co-habiting people (OR 0.75) compared to singles. Cases on early retirement redeemed most of all types of smoking cessation medication (OR 1.56), whereas cases on social security redeemed the least (OR 0.68).
Table 4 shows a conditional logistic regression for redeeming smoking cessation medication on at least one occasion. The OR for cases redeeming any type of smoking cessation medication was 6.22 [95\% CI 6.01-6.44] compared with controls. A similar finding was seen for all subtypes of smoking cessation medication.

Table 5 shows a conditional logistic regression for attempts to quit smoking. The OR for cases trying to quit smoking once was 5.82 [95\% CI 5.6-6.04] compared with controls.

\section{Discussion}

In this retrospective, national registry study, we provide, for the first time, detailed information on individual factors that play a role in patients with COPD regarding the choice of pharmacological smoking cessation treatment. We found that cases were more than six times more likely to redeem a prescription for any kind of smoking cessation medication, compared with their matched controls (OR 6.22). One of the most obvious reasons for the finding is probably that patients with COPD have felt the everyday bodily complications caused by smoking, which would probably make them more motivated to quit smoking compared with non-COPD controls. This is supported by a study by Melzer et al who found that patients with COPD were more prone to smoking cessation if they had symptoms of airway obstruction. ${ }^{40}$

We found that people with COPD tried to quit smoking more often than their lung healthy controls. Other studies have shown that patients with COPD experience a higher nicotine dependence. ${ }^{41,42}$ The combination of motivation to quit smoking and a high nicotine dependence might be a part of the explanation for our result.

A study by Van Eerd et al showed that there were no differences in quitting rates between lung healthy patients and patients with COPD, but that patients with COPD used smoking cessation medicine to quit smoking more often than their lung healthy controls. ${ }^{43}$ This result suggests that our finding of higher numbers of quitting attempts among patients with COPD, to some extent, might be explained by the fact that lung healthy smokers tend to choose nonpharmacological smoking cessation strategies.

National and regional guidelines in Denmark recommend that patients with COPD undergo at least annual follow-up visits to their general practitioner (GP) or an outpatient clinic. A mandatory part of the check-up is a (brief) discussion about the patient's smoking status and advice on smoking cessation. Discussing smoking 


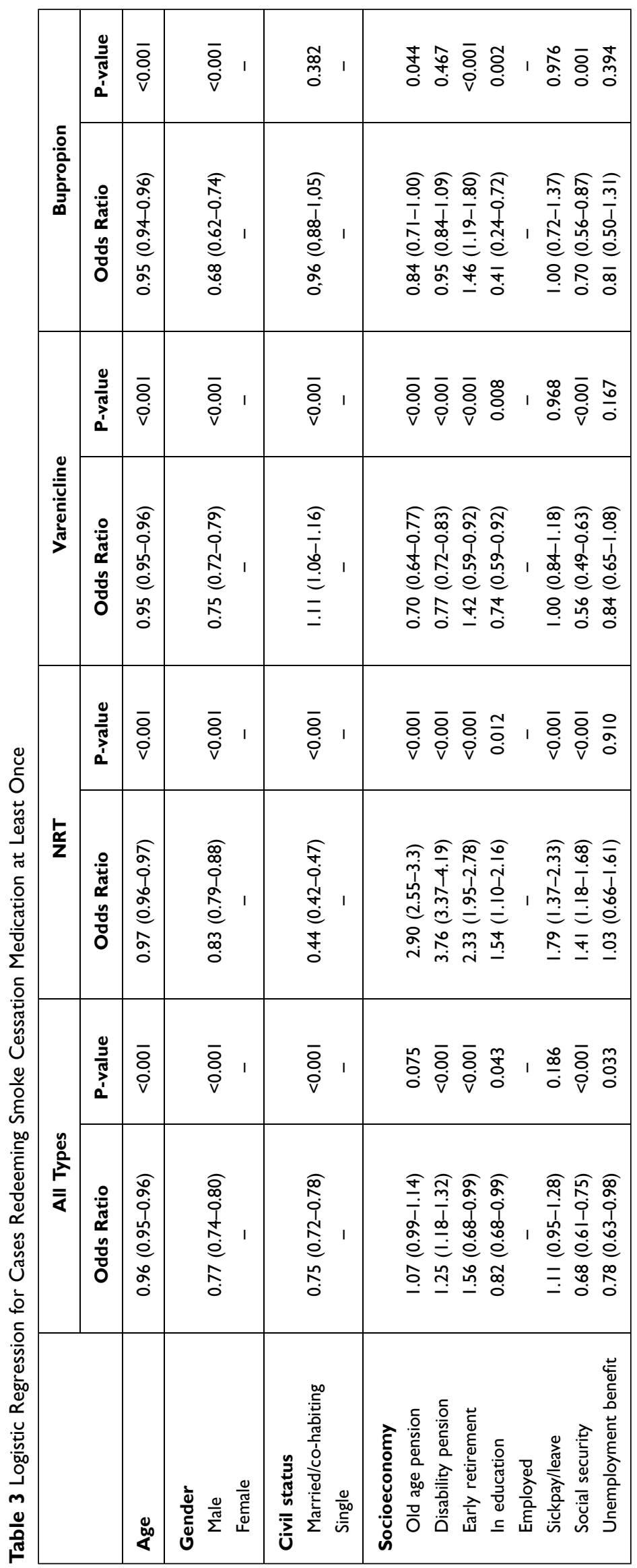


Table 4 Conditional Logistic Regression for Case-Control for Redeeming Smoking Cessation Medication at Least Once

\begin{tabular}{|c|c|c|c|c|c|c|c|c|}
\hline & \multicolumn{2}{|c|}{ All Types } & \multicolumn{2}{|c|}{ NRT } & \multicolumn{2}{|c|}{ Varenicline } & \multicolumn{2}{|c|}{ Bupropion } \\
\hline & Odds Ratio & P-value & Odds Ratio & P-value & Odds Ratio & P-value & Odds Ratio & P-value \\
\hline \multicolumn{9}{|l|}{ Redeemed prescription } \\
\hline Not collected & - & - & - & - & - & - & - & - \\
\hline Collected & $6.22(6.01-6.44)$ & $<0.001$ & $7.69(7.24-8.16)$ & $<0.001$ & $5.54(5.30-5.78)$ & $<0.001$ & $5.03(4.62-5.47)$ & $<0.001$ \\
\hline \multicolumn{9}{|l|}{ Redeemed prescription } \\
\hline 0 times & - & - & - & - & - & - & - & - \\
\hline I time & $5.69(5.43-5.97)$ & $<0.001$ & $7.43(6.85-8.06)$ & $<0.001$ & $5.23(4.93-5.56)$ & $<0.001$ & $5.15(4.67-5.68)$ & $<0.001$ \\
\hline$\geq 2$ times & $6.81(6.49-7.12)$ & $<0.001$ & $7.97(7.32-8.68)$ & $<0.001$ & $5.87(5.52-6.25)$ & $<0.001$ & $4.71(3.99-5.55)$ & $<0.001$ \\
\hline
\end{tabular}

Table 5 Logistic Regression Showing Attempts to Quit Smoking

\begin{tabular}{|l|c|c|c|c|}
\hline \multirow{2}{*}{ Attempts to Quit } & Case & Control & \multirow{2}{*}{ Odds Ratio } & \multirow{2}{*}{ P-value } \\
\cline { 2 - 5 } & n (\%) & n (\%) & - & - \\
\hline 0 & $114,941(87.88)$ & $246,905(97.89)$ & $5.82(5.6-6.04)$ & $<0.001$ \\
1 & $12,038(9.29)$ & $4315(1.71)$ & $7.80(7.14-8.52)$ & $<0.001$ \\
2 & $2626(2.01)$ & $714(0.28)$ & $9.08(7.66-10.76)$ & $<0.001$ \\
4 & $818(0.63)$ & $182(0.07)$ & $7.72(6.11-9.77)$ & $<0.001$ \\
\hline
\end{tabular}

status with a doctor has in several studies been shown to increase the probability of the doctor prescribing smoking cessation medication. ${ }^{44,45}$ These annual follow-up visits could partly explain why cases redeemed more prescriptions for smoking cessation medication than controls.

This study shows that young age increases the likelihood of redeeming a prescription for smoking cessation medicine. The finding is supported by a large study by Jordon et al with more than 180,000 participants. ${ }^{46}$ Their study showed that with rising age, the smokers were seeking a GP's advice to smoking cessation less frequently. They also found that in the GP's consultation room, the smoking cessation advice was given equally often to all age groups, but that younger patients ended up with a prescription for smoking cessation medicine more often.

The fact that females with COPD are more likely to redeem a prescription for any kind of smoking cessation medication compared with males with COPD has also been found by other research groups, but never in a COPD cohort size as in this study. ${ }^{47}$ In Denmark, the same percentage of men and women are daily smokers. Therefore, difference between genders in smoking prevalence cannot explain this finding. ${ }^{9}$ In a mixed population from USA, Canada, France, Italy, Germany, the Netherlands, Spain and the UK, Watson et al found that women were more likely than men to get smoking cessation advice. ${ }^{48}$ If this finding is applicable to the population in the present study, this could be a possible explanation for this finding.

Other studies have shown that high socio-economic status increases people's chances of using smoking cessation medicine. ${ }^{47}$ Surprisingly, we found that cases on disability pension, early retirement or sick pay redeemed most smoking cessation medication. A similar finding was seen in the control group. One of the explanations could be that people on disability pension or sick pay visit their GP practitioner more often because they have comorbidities. More contacts with the GP would provide more opportunities to discuss smoking cessation and to get a prescription for smoking cessation medicine.

We found that, while patients with COPD were six times more likely to redeem prescriptions for smoking cessation medication than were their controls, the proportion is still low - despite the fact that smoking cessation is the cornerstone of COPD treatment. Over a period of eight years, only $12.1 \%$ of patients with COPD tried to quit smoking using smoking cessation medication; $9.3 \%$ tried once, and only $2 \%$ tried twice. Considering the importance of smoking cessation and that $33 \%$ of people with COPD in Denmark are current smokers, the numbers of quitting attempts are discouraging. 


\section{Strengths and Limitations}

The strength of the study is that we have a complete national sample on all Danish patients with COPD followed in hospital.

Data on lung function among cases were not available for validation of COPD diagnosis. However, Thygesen et al showed that the positive predictive value of Danish National Patient Registry coding of COPD is near $100 \%{ }^{49}$

We have no information about smoking status among cases and controls. When we find that cases redeemed more than six times as much smoking cessation medication compared with controls, one of the reasons could be that the prevalence of both smokers and recent quitters among cases is higher than among controls. According to numbers from the Danish COPD database, DRKOL, 33\% of patients with COPD are current smokers. The prevalence of smokers in the general Danish population is $23 \%$, so it seems reasonable to estimate that this was also the prevalence in our control group. ${ }^{9}$ Thus, the difference in smoking status cannot fully explain the six times higher collection rates among patients with COPD.

Our data included all prescriptions redeemed in Denmark between 2009 and 2015. Varenicline was the most redeemed medicine in both groups, followed by NRT and, lastly, bupropion. Varenicline and bupropion are prescription drugs, but NRT can also be bought over-the-counter in Denmark, making it an easily accessible and very popular product. NRT can be bought while doing the grocery shopping, and a consultation with a health professional is not necessary. NRT can be bought in smaller amounts than either varenicline or bupropion, which makes the unit price lower. Our knowledge of the use of smoking cessation medication is limited to the number of redeemed prescriptions. NRT bought over the counter is unfortunately not registered and is therefore not included in our study. In 2015, only 3\% of NRT was bought on prescription. ${ }^{50}$ The number of redeemed prescriptions for varenicline and bupropion was not affected.

We have no data regarding non-pharmacological smoking cessation treatment, such as counseling or brief advice, since no national register in Denmark contains that kind of information. However, since the most effective smoking cessation strategy includes pharmacological treatment, our results are still of great clinical importance.

In our study, the inclusion criterion was a COPD diagnosis based on the ICD-10 code J44.x. Unfortunately, the ICD-10 coding is only used in the secondary sector. Patients with COPD who have never had contact with the secondary health care system will not be registered with the ICD-10 code J44.x. These patients were not included in the case group - and some could indeed be included in the control group. The people not included would be mainly patients with a less serious level of disease (GOLD-group A and B). Patients with higher disease level (GOLD-group $\mathrm{C}$ and $\mathrm{D}$ ) are routinely followed up at hospital outpatient clinics. It is well known that people with milder disease and fewer symptoms are not as keen to buy smoking cessation medication, and we therefore risk overestimating the number of patients with COPD using smoking cessation medication and thus a type 2 error. $^{47}$

\section{Conclusion}

In conclusion, we found patients with COPD to be six times more likely to redeem a prescription for smoking cessation medication compared with matched controls, although prevalence of smoking among patients with COPD (33\%) and the background population (23\%) does not differ significantly.

Young age, female gender, and being single were independent factors associated with an increased likelihood of redeeming a prescription for smoking cessation medication among patients with COPD.

As smoking cessation is of great importance in the treatment of patients with COPD, it is worrying that only $12 \%$ of the included patients with COPD redeemed smoking cessation medication during the seven-year study period. Our study indicates that there is substantial room for improvement in smoking cessation initiatives for the Danish population in general and specifically for patients with COPD.

\section{Funding}

The study was sponsored by Pfizer Denmark Aps.

\section{Disclosure}

Dea Kejlberg Andelius reports grants from Danish Society of Respiratory Medicine, during the conduct of the study. The authors report no other conflicts of interest in this work.

\section{References}

1. Kohansal R, Martinez-Camblor P, Agustí A, Sonia Buist A, Mannino DM, Soriano JB. The natural history of chronic airflow obstruction revisited: an analysis of the Framingham Offspring Cohort. Am J Respir Crit Care Med. 2009;180(1):3-10. doi:10.1164/ rccm.200901-0047OC 
2. Agustí A, Beasley R, Celli B, et al. Pocket guide to COPD diagnosis, management, and prevention: a guide for health care professionals. Global Initiative for Chronic Obstructive Lung Disease, Inc.; 2019:1-43.

3. Viegi G, Pistelli F, Sherrill DL, Maio S, Baldacci S, Carrozzi L. Definition, epidemiology and natural history of COPD. Eur Respir J. 2007;30(5):993-1013. doi:10.1183/09031936.00082507

4. Regions of Denmark. Danish Register of COPD. DrKOL Dansk register for Kronisk Obstruktiv Lungesygdom - National årsrapport 2018. National yearly rapport 2018. Reg Klin Kvalitetsudviklingsprogr; December, 2018:1-98. Available from: www.rkkp.dk. Accessed August 12, 2021.

5. Adeloye D, Chua S, Lee C, et al. Global and regional estimates of COPD prevalence: systematic review and meta-analysis. $J$ Glob Health. 2015;5(2). doi:10.7189/jogh.05.020415

6. Buist AS, McBurnie MA, Vollmer WM, et al. International variation in the prevalence of COPD (The BOLD Study): a population-based prevalence study. Lancet. 2007;370(9589):741-750. doi:10.1016/ S0140-6736(07)61377-4

7. Sikjær MG, Løkke A, Hilberg O. The influence of psychiatric disorders on the course of lung cancer, chronic obstructive pulmonary disease and tuberculosis. Respir Med. 2018;135:35-41. doi:10.1016/j. rmed.2017.12.012

8. Løkke A, Fabricius PG, Vestbo J, Marott JL, Lange P. Prevalence of chronic obstructive pulmonary disease in Copenhagen. Results from The Copenhagen City Heart Study. Ugeskr Laeger. 2007;169 (46):3956-3960

9. Danish Health Authority. Danskernes Rygevaner 2018; 2018. Smoking habits among Danish citizens 2018. Available from: https://www.sst.dk/da/udgivelser/2019/danskernes-rygevaner-2018. Accessed August 12, 2021.

10. Nielsen R, Johannessen A, Benediktsdottir B, Gislason T, Buist AS, Gulsvik A. Europe PMC funders group present and future costs of COPD in Iceland and Norway: results from the BOLD study. Eur Respir J. 2012;34(4):850-857. doi:10.1183/09031936.00166108.Present

11. Brogaard SL, Nielsen MBD, Nielsen LU, et al. Health care and social care costs of pneumonia in Denmark: a register-based study of all citizens and patients with COPD in three municipalities. Int $J$ COPD. 2015;10(1):2303-2309. doi:10.2147/COPD.S92133

12. Løkke A, Hilberg O, Tønnesen P, Ibsen R, Kjellberg J, Jennum P. Direct and indirect economic and health consequences of COPD in Denmark: a national register-based study: 1998-2010. BMJ Open. 2014;4(1):1-7. doi:10.1136/bmjopen-2013-004069

13. Tashkin DP, Murray RP. Smoking cessation in chronic obstructive pulmonary disease. Respir Med. 2009;103(7):963-974. doi:10.1016/j. rmed.2009.02.013

14. Mannino DM, Watt G, Hole D, et al. The Natural history ofchronic obstructive pulmonary disease. Chronic Obdtr Pulm Dis. 2008;(June) 115-123. doi:10.1002/9780470755976.ch10

15. Tønnesen P. Smoking cessation and COPD. Eur Respir Rev. 2013;22 (127):37-43. doi:10.1183/09059180.00007212

16. Scanlon PD, Connett JE, Waller LA, et al. Smoking cessation and lung function in mild-to-moderate chronic obstructive pulmonary disease: the lung health study. Am J Respir Crit Care Med. 2000;161(2I):381-390. doi:10.1164/ajrccm.161.2.9901044

17. Cahill K, Stevens S, Perera R, Lancaster T. Pharmacological interventions for smoking cessation: an overview and network meta-analysis. Cochrane Database Syst Rev. 2013;2013(5):N.PA-N. PA. doi:10.1002/14651858.CD009329.pub2

18. Vogelmeier CF, Criner GJ, Martínez FJ, et al. Global strategy for the diagnosis, management, and prevention of chronic obstructive lung disease 2017 report: GOLD executive summary. Arch Bronconeumol. 2017;53(3):128-149. doi:10.1016/j.arbr.2017.02.001

19. O'Donnell DE, Aaron S, Bourbeau J, et al. Canadian Thoracic Society recommendations for management of chronic obstructive pulmonary disease - 2003. Can Respir J. 2003;10(SUPPL.A):5B32B. doi: $10.1155 / 2003 / 567598$
20. Xu X, Dockery DW, Ware JH, Speizer FE, Ferris BG. Effects of cigarette smoking on rate of loss of pulmonary function in adults: a longitudinal assessment. Am Rev Respir Dis. 1992;146 (5):1345-1348. doi:10.1164/ajrccm/146.5_Pt_1.1345

21. Camilli AE, Burrows B, Knudson RJ, Lyle SK, Lebowitz MD. Longitudinal changes in forced expiratory volume in one second in adults. Effects of smoking and smoking cessation. Am Rev Respir Dis. 1987;135(4I):794-799. doi:10.1164/arrd.1987.135.4.794

22. Nisa L, Giger R. Practice clinical images - Lingua plicata. Cmaj. 2012;184(3):2012. doi:10.1503/cmaj.111255

23. Pezzuto A, Carico E. Effectiveness of smoking cessation in smokers with COPD and nocturnal oxygen desaturation: functional analysis. Clin Respir J. 2020;14(1):29-34. doi:10.1111/crj.13096

24. Godtfredsen NS, Tønnesen P. The effect of smoking cessation related to COPD. Ugeskr Laeger. 2013;175(18):1266-1269.

25. Tøttenborg SS, Thomsen RW, Johnsen SP, Nielsen H, Lange P. Determinants of smoking cessation in patients with COPD treated in the outpatient setting. Chest. 2016;150(3):554-562. doi:10.1016/j. chest.2016.05.020

26. Górecka D, Bednarek M, Nowiński A, Puścińska E, GoljanGeremek A, Zieliński J. Diagnosis of airflow limitation combined with smoking cessation advice increases stop-smoking rate. Chest. 2003;123(6):1916-1923. doi:10.1378/chest.123.6.1916

27. Danish Health Authority. Behandling Af Tobaksafhængighed Anbefalinger Til En Styrket Klinisk Praksis. Treatment of tobacco addiction - Recommandations to a better clinical practice; 2011. Available from: https://www.sst.dk/-/media/Udgivelser/2011/ Pub12011/BOFO/Tobak/Behandling-af-tobaksafhaengighedAnbefalinger-til-en-styrket-klinisk-praksis.ashx?la=da\&hash= 2CF9B6950AE2DC413BD2A0C10C3307EDB147D5ED. Accessed August 14, 2021.

28. Gonzales D, Rennard SI, Nides M, et al. Varenicline, an $\alpha 4 \beta 2$ nicotinic acetylcholine receptor partial agonist, vs sustained-release bupropion and placebo for smoking cessation: a randomized controlled trial. J Am Med Assoc. 2006;296(1):47-55. doi:10.1001/ jama.296.1.47

29. Barry K, Finke J. Nicotine replacement therapy for smoking cessation. Am Fam Physician. 2020;102(1):17-18. doi:10.1002/ 14651858.CD000146.pub4.

30. Tønnesen P. Which drug to be used in smoking cessation? Pol Arch Med Wewn. 2008;118(6):373-376. doi:10.20452/pamw.420

31. Hajek P. Long-term use of nicotine chewing gum. JAMA. 1988;260 (11): 1593. doi:10.1001/jama.1988.03410110101035

32. Hummel K, Nagelhout GE, Fong GT, et al. Quitting activity and use of cessation assistance reported by smokers in eight European countries: findings from the EUREST-PLUS ITC Europe Surveys. Tob Induc Dis. 2018;16:1-17. doi:10.18332/tid/98912

33. Tavakoli H, Johnson KM, Fitzgerald JM, et al. Trends in prescriptions and costs of inhaled medications in chronic obstructive pulmonary disease: a 19-year population-based study from Canada. Int J COPD. 2019;14:2003-2013. doi:10.2147/COPD.S210897

34. Reisinger SA, Kamel S, Seiber E, Klein EG, Paskett ED, Wewers ME. Cost-effectiveness of community-based tobacco dependence treatment interventions: initial findings of a systematic review. Prev Chronic Dis. 2019;16(12):1-18. doi:10.5888/pcd16.190232

35. Danish Health Authority. Danskernes Rygevaner 2015 - udvalgte resultater; 2015:19 20. Smoking habits among Danish Citizens 2015 - selected results. . Available from: https://www.sst.dk/da/udgivelser/ 2016/ /media/8CEB6CBBE22B4488817EE6259A681F67.ashx. Accessed August 12, 2021.

36. Schmidt M, Schmidt SAJ, Sandegaard JL, Ehrenstein V, Pedersen L, Sørensen HT. The Danish National patient registry: a review of content, data quality, and research potential. Clin Epidemiol. 2015;7:449-490. doi:10.2147/CLEP.S91125

37. Pedersen CB. The Danish civil registration system. Scand J Public Health. 2011;39(7):22-25. doi:10.1177/1403494810387965 
38. Wallach Kildemoes H, Toft sørensen H, Hallas J. The Danish national prescription registry. Scand J Public Health. 2011;39(7):38-41. doi:10.1177/1403494810394717

39. Statistics Denmark. Times variable - Socio 13. https://www.dst.dk/da/ Statistik/dokumentation/Times/personindkomst/socio13. Accessed August 14, 2021

40. Melzer AC, Feemster LC, Crothers K, et al. Respiratory and bronchitic symptoms predict intention to quit smoking among current smokers with, and at risk for, chronic obstructive pulmonary disease. Ann Am Thorac Soc. 2016;13(9):1490-1496. doi:10.1513/AnnalsA TS.201601-075OC

41. Vozoris NT, Stanbrook MB. Smoking prevalence, behaviours, and cessation among individuals with COPD or asthma. Respir Med. 2011;105(3):477-484. doi:10.1016/j.rmed.2010.08.011

42. Jiménez-Ruiz CA, Masa F, Miravitlles M, et al. Smoking characteristics: differences in attitudes and dependence between healthy smokers and smokers with COPD. Chest. 2001;119(5):1365-1370. doi:10.1378/chest.119.5.1365

43. Van Eerd EAM, Van Rossem CR, Spigt MG, Wesseling G, Van Schayck OCP, Kotz D. Do we need tailored smoking cessation interventions for smokers with COPD? A comparative study of smokers with and without COPD regarding factors associated with tobacco smoking. Respiration. 2015;90(3):211-219. doi:10.1159/000398816

44. Gorin SS, Heck JE. Meta-analysis of the efficacy of tobacco counseling by health care providers. Cancer Epidemiol Biomarkers Prev. 2004;13(12):2012-2022.
45. Stead LF, Bergson G, Lancaster T. Physician advice for smoking cessation. Cochrane Database Syst Rev. 2008;2:CD000165. doi:10.1002/14651858.CD000165.pub3

46. Jordan H, Hidajat M, Payne N, Adams J, White M, Ben-Shlomo Y. What are older smokers' attitudes to quitting and how are they managed in primary care? An analysis of the cross-sectional English Smoking Toolkit Study. BMJ Open. 2017;7(11):1-9. doi:10.1136/bmjopen-2017-018150

47. Tøttenborg SS, Clark AJ, Thomsen RW, Johnsen SP, Lange P. Socioeconomic inequality in the use of prescription medications for smoking cessation among patients with COPD: a nationwide study. Int J COPD. 2018;13:1775-1781. ((Tottenborg, Clark, Lange) Department of Public Health, Section of Social Medicine, University of Copenhagen, Copenhagen, Denmark). doi:10.2147/ COPD.S158954

48. Watson L, Vestbo J, Postma DS, et al. Gender differences in the management and experience of Chronic Obstructive Pulmonary Disease. Respir Med. 2004;98(12):1207-1213. doi:10.1016/j. rmed.2004.05.004

49. Thygesen SK, Christiansen CF, Christensen S, Lash TL, Sørensen HT. The predictive value of ICD-10 diagnostic coding used to assess Charlson comorbidity index conditions in the population-based Danish National Registry of Patients. BMC Med Res Methodol. 2011;11(1):83. doi:10.1186/1471-2288-11-83

50. The Danish Health Data Authority. medstat.dk. Available from: https://medstat.dk/en. Accessed August 14, 2021

\section{Publish your work in this journal}

The International Journal of COPD is an international, peer-reviewed journal of therapeutics and pharmacology focusing on concise rapid reporting of clinical studies and reviews in COPD. Special focus is given to the pathophysiological processes underlying the disease, intervention programs, patient focused education, and self management protocols. This journal is indexed on PubMed Central, MedLine and CAS. The manuscript management system is completely online and includes a very quick and fair peer-review system, which is all easy to use. Visit http://www.dovepress.com/testimonials.php to read real quotes from published authors. 